\title{
Impacts of air pollutants from fire and non-fire emissions on the regional air quality in Southeast Asia
}

\section{Hsiang-He Lee et al.}

Correspondence to: Hsiang-He Lee (hsiang-he@smart.mit.edu)

The copyright of individual parts of the supplement might differ from the CC BY 4.0 License. 


\section{S1. Uncertainty analysis of modeled LVDs}

Since a full-scale forward-integrating uncertainty analysis based on WRF-Chem model would extremely expensive computationally, we have adopted a method for dichotomous (yes or no LVDs) cases and then give a contingency table (Table S6) to address model evaluation and to quantify model performance.

We have estimated accuracy based on the Eq. (S1):

$$
\text { Accuracy }=\frac{\text { hits }+ \text { correct negatives }}{\text { hits }+ \text { misses }+ \text { false alarms }+ \text { correct negatives }}
$$

Accuracy here is also called fraction correct, which is easy to evaluate model prediction. However, it can be misleading for some cases since it is heavily influenced by the most common category, usually "no event" in the case of LVD. Hence, we have provided threat score in this study as well. Based on the equation of threat score (or critical success index), we can measure the fraction of observed and/or modeled LVDs that were correctly predicted. Threat score also can be referred as the accuracy when correct negatives have been removed from consideration, that is, threat score only concerns modeled LVDs that count.

$$
\text { Threat Score }=\frac{\text { hits }}{\text { hits+misses }+ \text { false alarms }}
$$

Figure S8 shows the mean value of accuracy and threat score of modeled LVDs among 50 ASEAN cities in three experiments: FF, BB, and FFBB. Since the category of correct negatives is heavily counted in the accuracy, the values are also twice as high as the threat scores. Basically, BB has the lowest threat score while FFBB has the highest score as expected. 


\section{S2. The impact of fire and non-fire aerosols on regional climate}

Besides influencing surface and air temperature through scattering and absorbing solar radiation, aerosols can also alter the spatiotemporal patterns of precipitation via aerosol direct and indirect effects (Wang, 2015). Over the modeled domain, rainfall (in quantity) mainly comes from convective clouds. When the model is configured with a relatively coarse resolution as adopted in our study, however, the convective precipitation process is calculated through the cumulus parameterization of the model, which follows a mass-flux approach to diagnose rainfall and does not interact with aerosols. Despite of this drawback, aerosols can still influence the radiation budget through their direct effect. The thermodynamic consequences of this effect can further influence the cloud formation. On the other hand, the model does contain aerosol-cloud microphysical interaction for stratiform clouds; therefore, aerosols can influence these clouds through the so-called indirect effects by providing cloud condensation nuclei for cloud droplets to form. Hence, cumulus rainfall can be still affected indirectly through dynamical and thermodynamic processes initiated by either aerosol direct effects, indirect effects in stratiform clouds, or both.

By comparing the precipitation in FF and FFBB, we have examined the impact of the extra forcing from fire aerosols on precipitation in the modeled Southeast Asia domain $\left(10^{\circ} \mathrm{S}-20^{\circ} \mathrm{N}\right.$ in latitude, $90^{\circ} \mathrm{E}-150^{\circ} \mathrm{E}$ in longitude). Non-fire aerosols provide a baseline pattern because of the persistency of fossil fuel emissions, while biomass burning emissions load additional aerosols in the air to alter total aerosol radiative forcing, which then would change precipitation. Through aerosol direct and indirect effects, the difference of monthly regional mean downward shortwave radiation at surface is $8.8 \mathrm{~W} \mathrm{~m}^{-2}\left(232.6 \mathrm{~W} \mathrm{~m}^{-2}\right.$ in $\mathrm{FF}$ versus $223.8 \mathrm{~W} \mathrm{~m}^{-2}$ in FFBB; Fig. S9). The data are calculated over land only. Owing to 
the reduction of surface incoming solar radiation by fire aerosols, surface skin temperature is $0.2 \mathrm{~K}$ lower in FFBB than in FF (Fig. S10). Lower surface temperature brought by fire aerosols would suppress convection (Berg et al., 2013). As a result, the model produced a lower monthly regional mean precipitation in FFBB than in FF by $0.2 \mathrm{~mm}^{\text {day }}{ }^{-1}$ over land (11.15 mm day ${ }^{-1}$ versus $11.35 \mathrm{~mm} \mathrm{day}^{-1}$; Fig. S11), with the most substantial rainfall changes occurring in the fire emission regions of Sumatra and Borneo. We also find higher cloud water mass in FFBB, which has stronger radiative forcing than aerosols. Nevertheless, further study using a cloud-resolving simulation is necessary. 
Table S1. Equations for the calculation of 24-hr average $\mathrm{PM}_{10}$ concentration $\left(\mu \mathrm{g} \mathrm{m}^{-3}\right)$ based on Air Quality Index (AQI) number obtained from the website of Ministry of Natural Resources and Environment, Department of Environment, Malaysia (Malaysia, 2000).

\begin{tabular}{c|l}
\hline $\mathrm{AQI}$ & \multicolumn{1}{|c}{ Equation } \\
\hline $0-50$ & $\mathrm{PM}_{10}=\mathrm{AQI}$ \\
$51-100$ & $\mathrm{PM}_{10}=(\mathrm{AQI}-50) \times 2+50$ \\
$101-200$ & $\mathrm{PM}_{10}=(\mathrm{AQI}-100) \times 2+150$ \\
$201-300$ & $\mathrm{PM}_{10}=(\mathrm{AQI}-200) / 1.4286+350$ \\
$301-400$ & $\mathrm{PM}_{10}=(\mathrm{AQI}-300) / 1.25+420$ \\
$401-500$ & $\mathrm{PM}_{10}=(\mathrm{AQI}-400)+500$ \\
\hline
\end{tabular}


Table S2. Sampling period of Surface PARTiculate mAtter Network (SPARTAN) stations in Southeast Asia and available compositional features.

\section{Available period Composition}

\begin{tabular}{|c|c|c|}
\hline Hanoi & May 2015 - present & \\
\hline Singapore & July 2015 - present & $\begin{array}{l}\mathrm{PM}_{2.5} \text {, Ammoniated Sulfate, Ammonium } \\
\text { Nitrate, Crustal Material, Residual } \\
\text { Material, Sea Salt, Equivalent Black }\end{array}$ \\
\hline Bandung & January 2014 - present & $\begin{array}{l}\text { Carbon, Trace Element Oxides, Particle- } \\
\text { Bound Water }(\mathrm{RH}=0.35)\end{array}$ \\
\hline Manila & February 2014 - present & \\
\hline
\end{tabular}


Table S3. Mean annual emissions and modeled concentration of $\mathrm{BC}, \mathrm{OC}, \mathrm{SO}_{2}, \mathrm{CO}$ and $\mathrm{NO}_{2}$ from 2006 REAS and EDGAR emission inventories in the simulated domain.

\begin{tabular}{c|c|c|c|c}
\hline \multirow{2}{*}{} & \multicolumn{2}{|c|}{ REAS } & \multicolumn{2}{c}{ EDGAR } \\
\cline { 2 - 5 } & $\begin{array}{c}\text { Emissions } \\
\text { (Tg/year) }\end{array}$ & $\begin{array}{c}\text { Modeled conc. } \\
\left(\mathrm{ug} / \mathrm{m}^{3} \text { or } \mathrm{ppmv}\right)\end{array}$ & $\begin{array}{c}\text { Emissions } \\
(\mathrm{Tg} / \mathrm{year})\end{array}$ & $\begin{array}{c}\text { Modeled conc. } \\
\left(\mathrm{ug} / \mathrm{m}^{3} \text { or ppmv) }\right.\end{array}$ \\
\hline $\mathrm{OC}$ & 0.12 & 0.1131 & 0.15 & 0.1487 \\
$\mathrm{BC}$ & 0.036 & 0.0311 & 0.065 & 0.0643 \\
$\mathrm{SO}_{2}$ & 0.43 & $1.03 \times 10^{-4}$ & 0.65 & $2.01 \times 10^{-4}$ \\
$\mathrm{NO}_{2}$ & 0.3 & $4.94 \times 10^{-4}$ & 0.205 & $4.83 \times 10^{-4}$ \\
$\mathrm{CO}$ & 3.53 & $8.10 \times 10^{-2}$ & 7.48 & $8.72 \times 10^{-2}$ \\
\hline
\end{tabular}


Table S4. Comparison of the Air Quality Index (AQI) values with level of pollution index category and breakpoints for AQI derived from modeled 24-hr $\mathrm{PM}_{2.5}\left(\mu \mathrm{g} \mathrm{m}^{-3}\right)$ and modeled 9-hr $\mathrm{O}_{3}$ (ppb).

\begin{tabular}{c|c|c|c}
\hline Index Category & AQI & $24-\mathrm{hr} \mathrm{PM}_{2.5}\left(\mu \mathrm{g} / \mathrm{m}^{3}\right)$ & $9-\mathrm{hr} \mathrm{O}_{3}(\mathrm{ppb})$ \\
\hline Good & $0-50$ & $0.0-12.0$ & $0-59$ \\
Moderate & $51-100$ & $12.1-35.4$ & $60-75$ \\
Unhealthy & $101-200$ & $35.5-150.4$ & $76-115$ \\
Very Unhealthy & $201-300$ & $150.5-250.4$ & $116-374$ \\
Hazardous & $301-400$ & $250.5-350.4$ & $/$ \\
Hazardous & $401-500$ & $350.5-500.4$ & $/$ \\
\hline
\end{tabular}


Table S5. Features are used to train Machine Learning algorithms for Changi, Seletar and Paya Labar data.

\begin{tabular}{|c|c|}
\hline Features for Changi & Features for Seletar and Paya Labar \\
\hline Hotspot count in mainland Southeast Asia (HS_M) & Hotspot count in mainland Southeast Asia (HS_M) \\
\hline Hotspot count in Sumatra (HS_S) & Hotspot count in Sumatra (HS_S) \\
\hline Hotspot count in Borneo (HS_B) & Hotspot count in Borneo (HS_B) \\
\hline Month (Month) & Month (Month) \\
\hline Wind direction (WD) & Wind direction (WD) \\
\hline Weather condition $^{\mathrm{a}}$ (SRV) & Weather condition $^{\mathrm{a}}$ (SRV) \\
\hline Classified precipitation $^{\mathrm{b}}(\mathrm{PPT})$ & Classified wind speed ${ }^{\mathrm{c}}(\mathrm{WS})$ \\
\hline Classified wind speed ${ }^{\mathrm{c}}(\mathrm{WS})$ & Classified relative humidity ${ }^{\mathrm{d}}(\mathrm{RH})$ \\
\hline Classified relative humidity ${ }^{\mathrm{d}}(\mathrm{RH})$ & 5-day continuous rainfall in mainland Southeast Asia (5PPT_M) \\
\hline Classified pressure $^{\mathrm{e}}$ (Pres) & 5-day continuous rainfall in Sumatra (5PPT_S) \\
\hline Classified dew point ${ }^{\mathrm{f}}($ Dtemp) & 5-day continuous rainfall in Borneo (5PPT_B) \\
\hline Classified temperature $^{\mathrm{g}}$ (Temp) & 10-day continuous rainfall in mainland Southeast Asia (10PPT_M) \\
\hline 5-day continuous rainfall in mainland Southeast Asia (5PPT_M) & 10-day continuous rainfall in Sumatra (10PPT_S) \\
\hline 5-day continuous rainfall in Sumatra (5PPT_S) & 10-day continuous rainfall in Borneo (10PPT_B) \\
\hline \multicolumn{2}{|l|}{ 5-day continuous rainfall in Borneo (5PPT_S) } \\
\hline \multicolumn{2}{|l|}{ 10-day continuous rainfall in mainland Southeast Asia (10PPT_M) } \\
\hline 10-day continuous rainfall in Sumatra (10PPT_S) & \\
\hline 10-day continuous rainfall in Borneo (10PPT_B) & \\
\hline
\end{tabular}

${ }^{a}$ Based on Allwine and Whiteman (1994) to classify weather condition to recirculation, ventilation, and stagnation.

${ }^{\mathrm{b}}$ Precipitation has been classified into 3 categories and the breakpoints are 0 and $100 \mathrm{~mm} \mathrm{day}^{-1}$.

${ }^{\mathrm{c}}$ Wind speed has been classified into 3 categories and the breakpoints are 5 and $10 \mathrm{~m} \mathrm{sec}^{-1}$.

${ }^{\mathrm{d}}$ Relative humidity has been classified into 4 categories and the breakpoints are 70, 80, and 90\%.

${ }^{\mathrm{e}}$ Pressure has been classified into 3 categories and the breakpoints are 1005 and $1010 \mathrm{mb}$.

${ }^{\mathrm{f}}$ Dew point has been classified into 3 categories and the breakpoints are 24 and $26^{\circ} \mathrm{C}$.

${ }^{\mathrm{g}}$ Temperature has been classified into 4 categories and the breakpoints are $25,27.8$, and $29^{\circ} \mathrm{C}$. 
Table S6. Contingency table for dichotomous (yes or no LVDs) cases

\begin{tabular}{|c|c|c|c|}
\hline & \multicolumn{2}{|c|}{ Observed LVD } \\
\hline & & yes & no \\
\hline \multirow{2}{*}{$\begin{array}{l}\text { Modeled } \\
\text { LVD }\end{array}$} & yes & hits & false alarms \\
\hline & no & misses & $\begin{array}{c}\text { correct } \\
\text { negatives }\end{array}$ \\
\hline
\end{tabular}


(a)
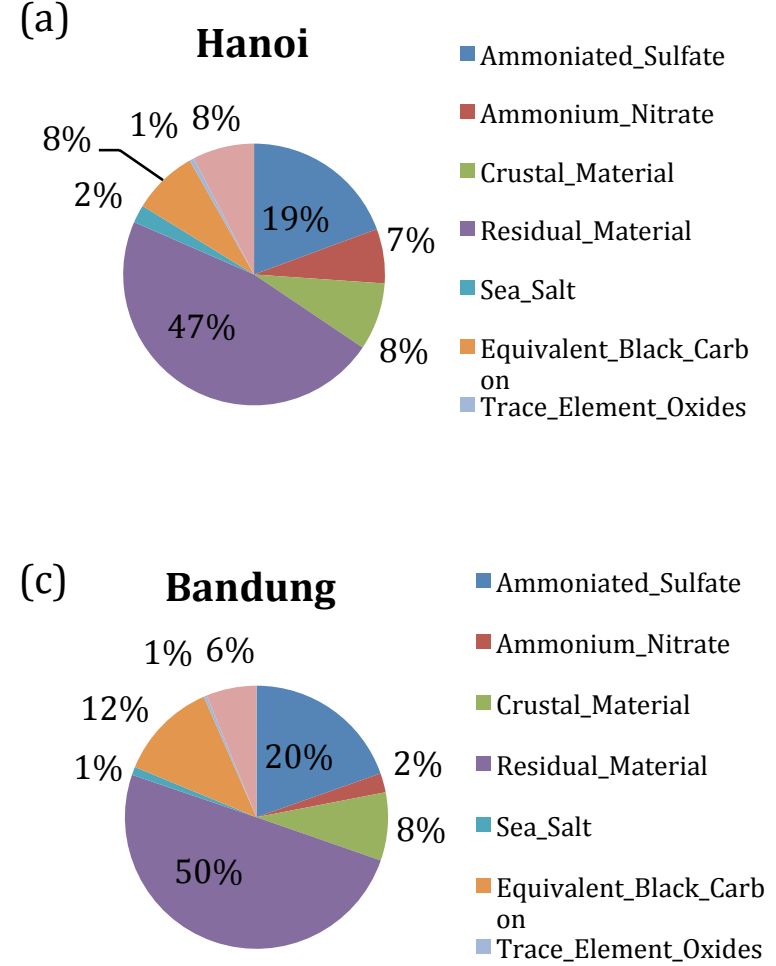
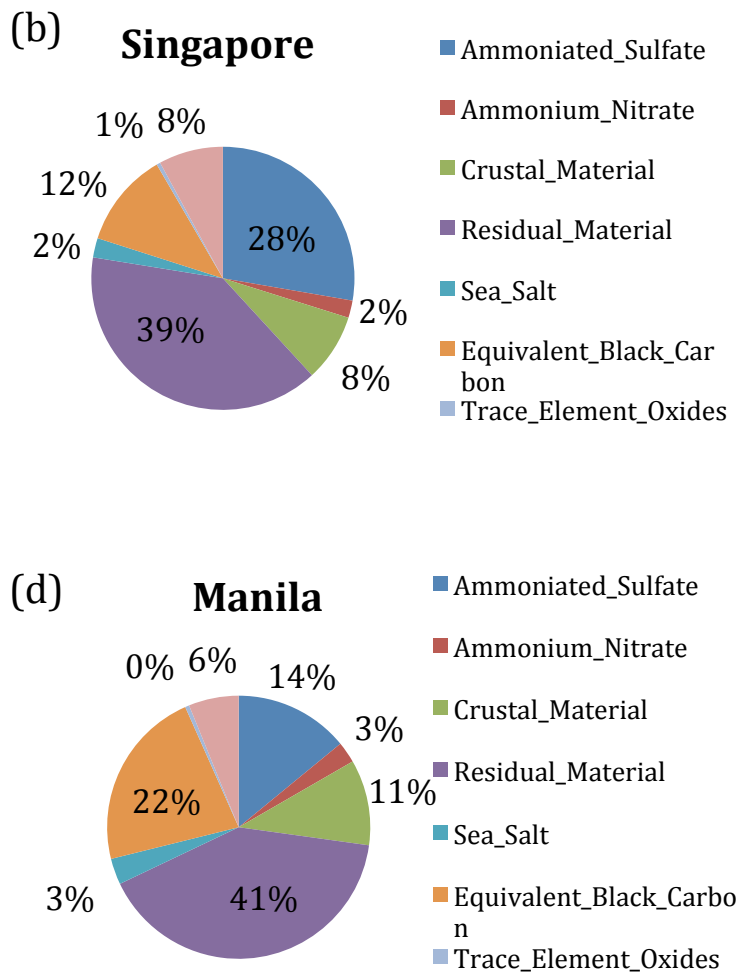

Figure S1. Pie chart of chemical components of $\mathrm{PM}_{2.5}$ from the Surface PARTiculate mAtter Network (SPARTAN) filter samples in (a) Hanoi (Vietnam), (b) Singapore (Singapore), (c) Bandung (Indonesia), and (d) Manila (Philippines). 
(a)

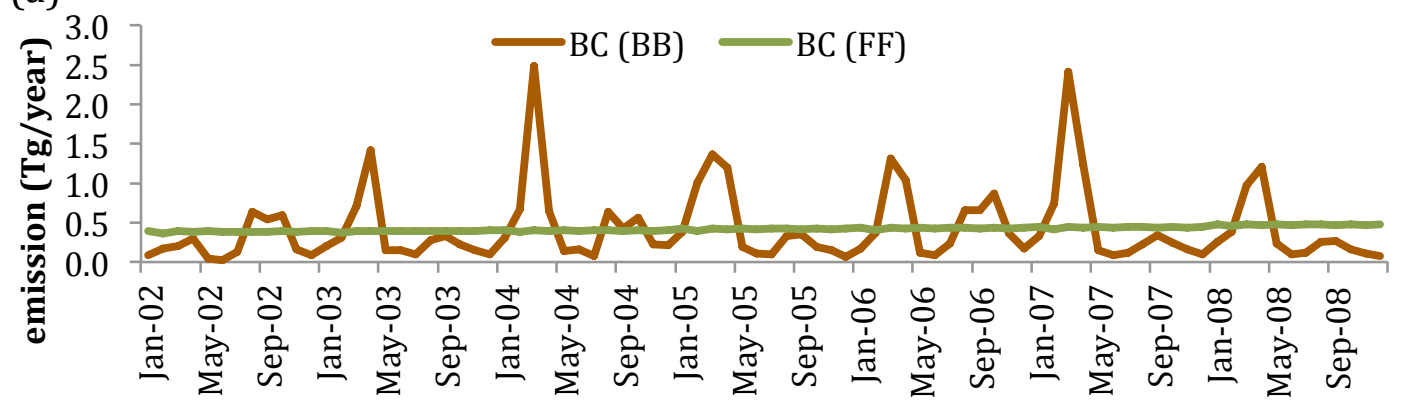

(b)

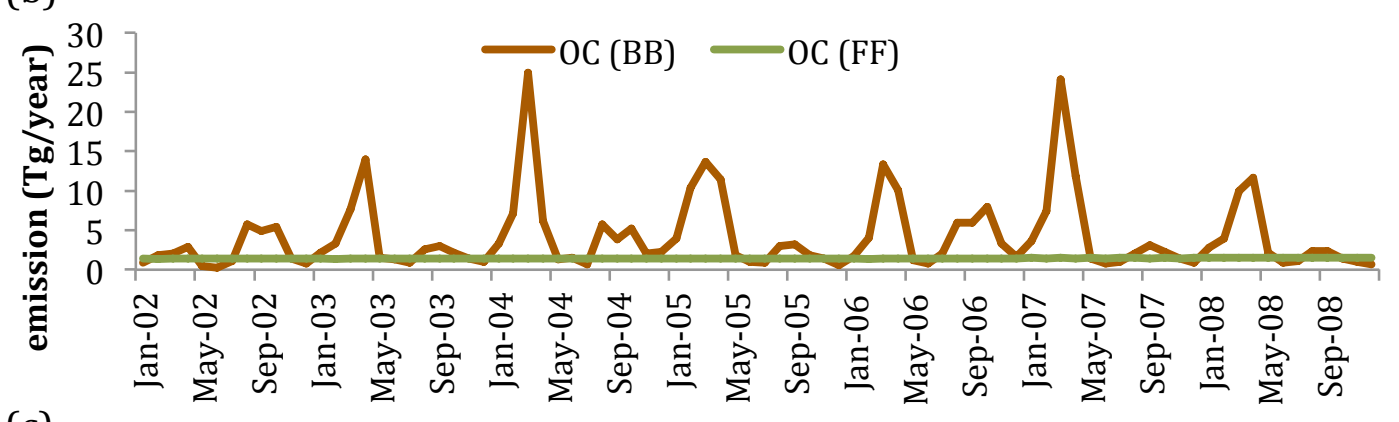

(c)

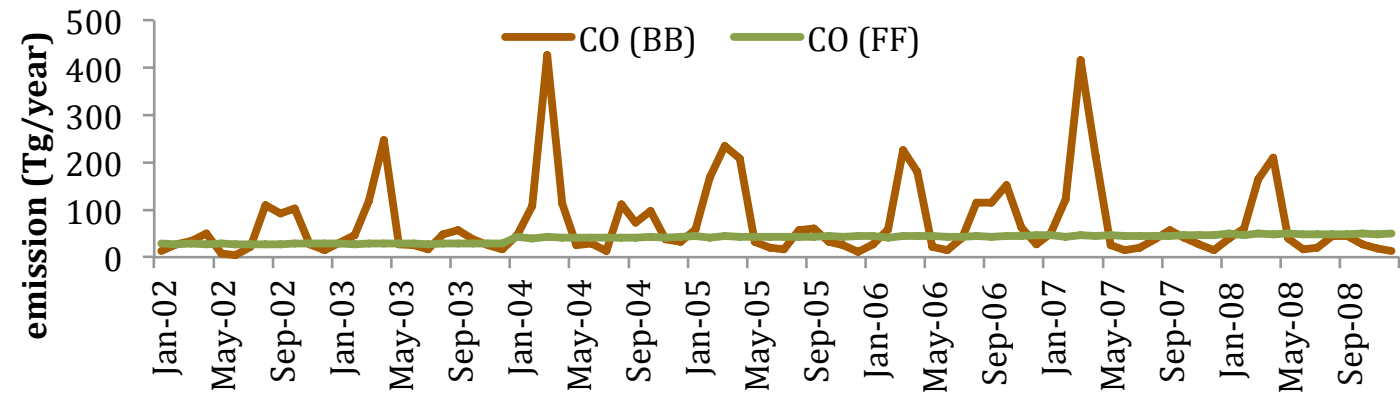

(d)

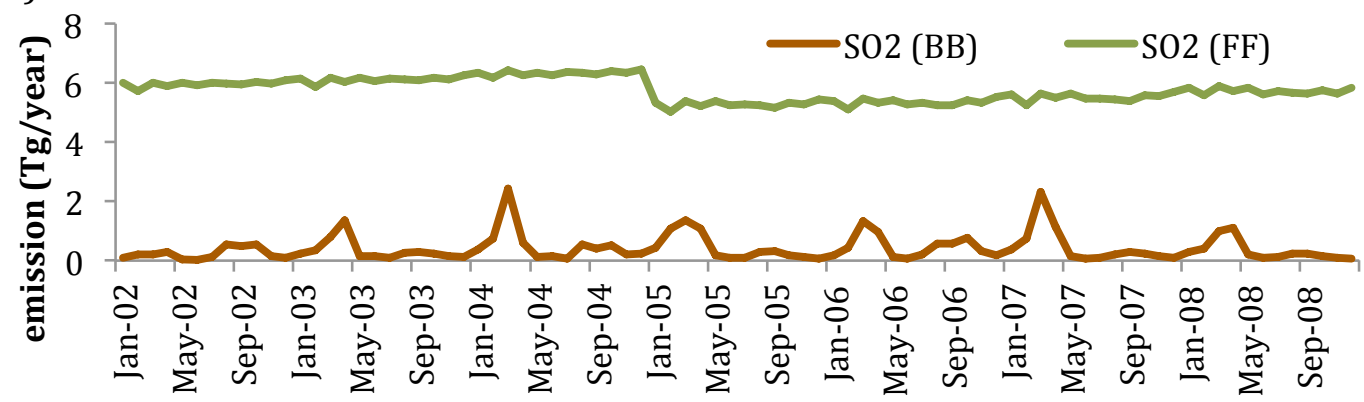

(e)

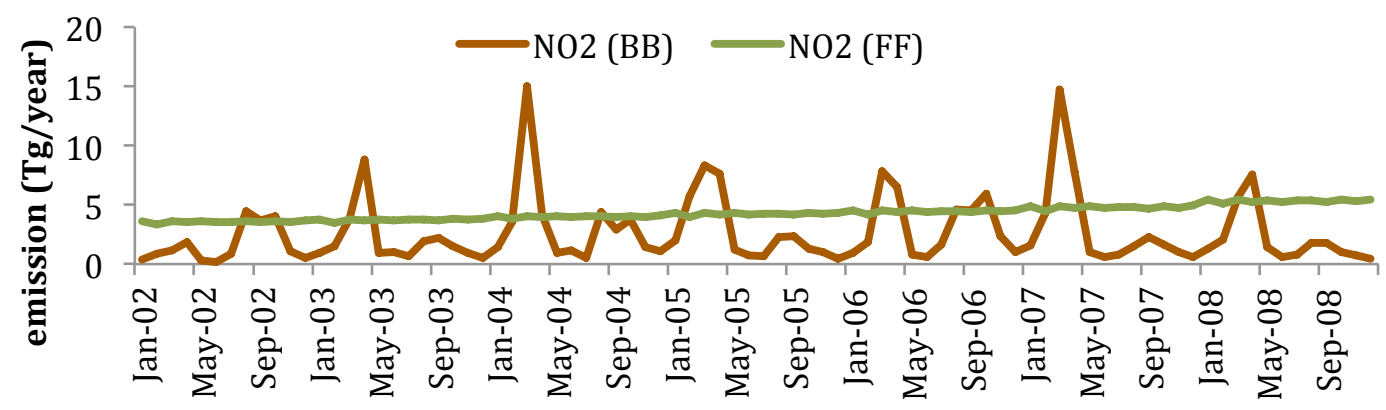


Figure S2. Time serious of domain averaged monthly (a) black carbon (BC), (b) organic carbon (OC), (c) carbon monoxide (CO), (d) sulfur dioxide $\left(\mathrm{SO}_{2}\right)$ and (e) nitrogen dioxide $\left(\mathrm{NO}_{2}\right)$ emission $\left(\mathrm{Tg} \mathrm{year}^{-1}\right)$ from biomass burning $(\mathrm{BB}$; red lines) and fossil fuel (FF; green lines) emission inventories during 2002-2008. 


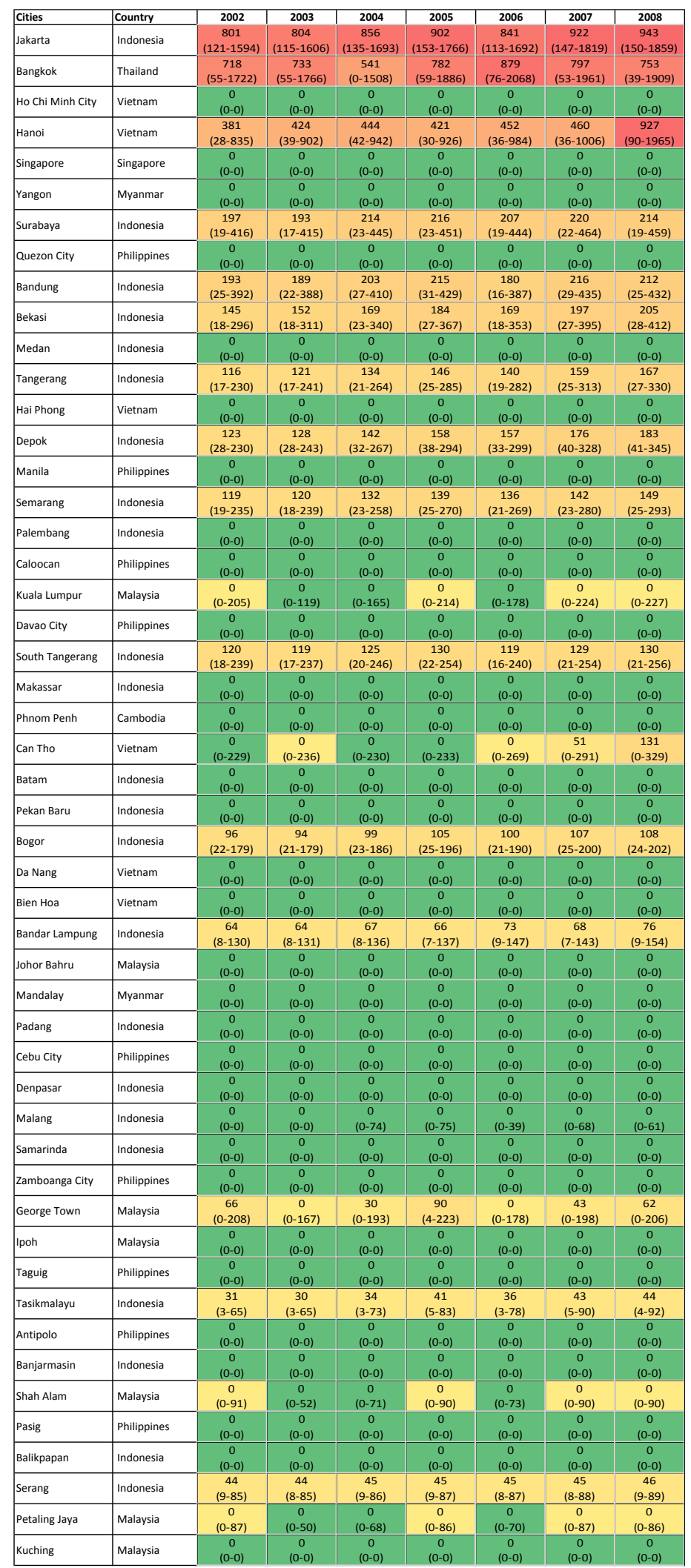

Figure S3. Premature mortality in different years from 2002 to 2008 and cities in Association of Southeast Asian Nations (ASEAN) due to exposures $\mathrm{PM}_{2.5}$ in $\mathrm{FF}(95 \%$ confidence intervals). Colors from green to red represent relative number scale. 


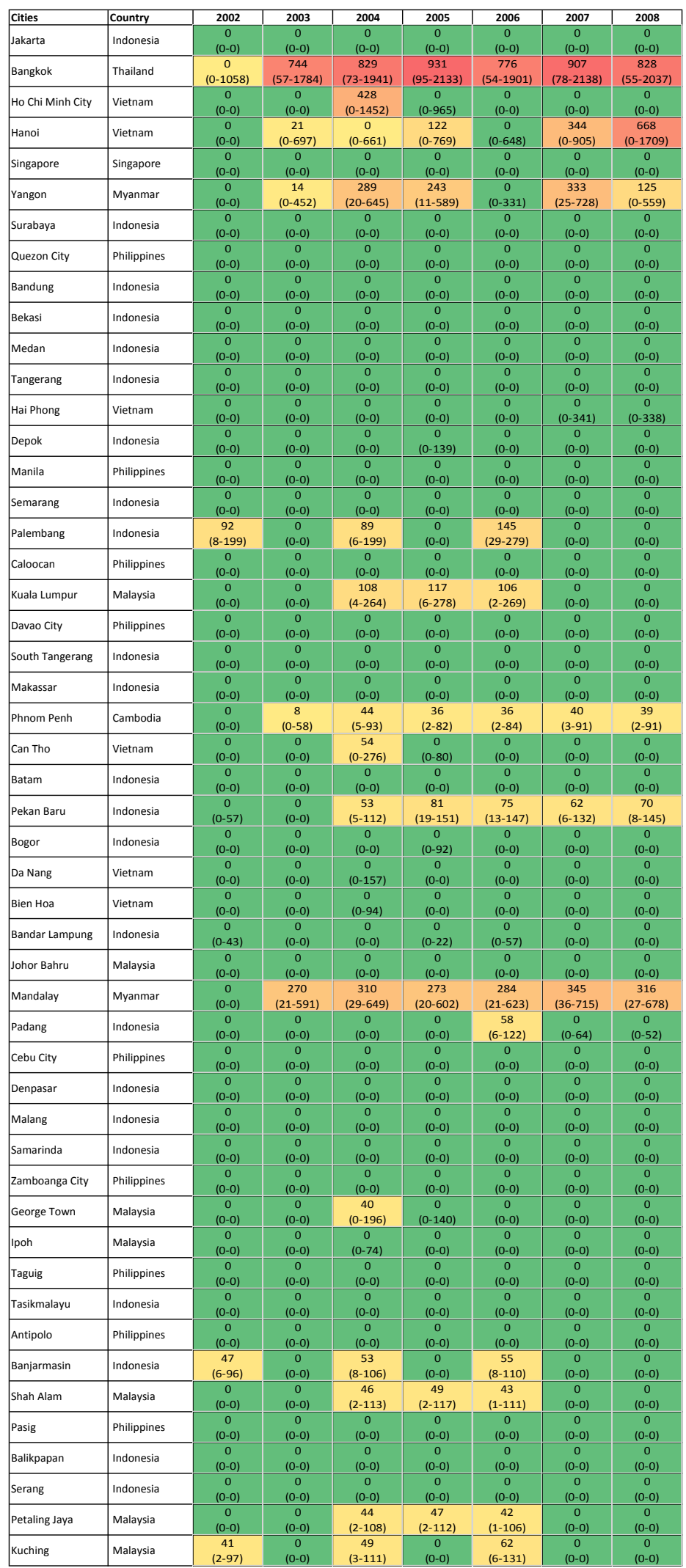

Figure S4. Same as Fig. S3 but $\mathrm{PM}_{2.5}$ in BB. 
(a)

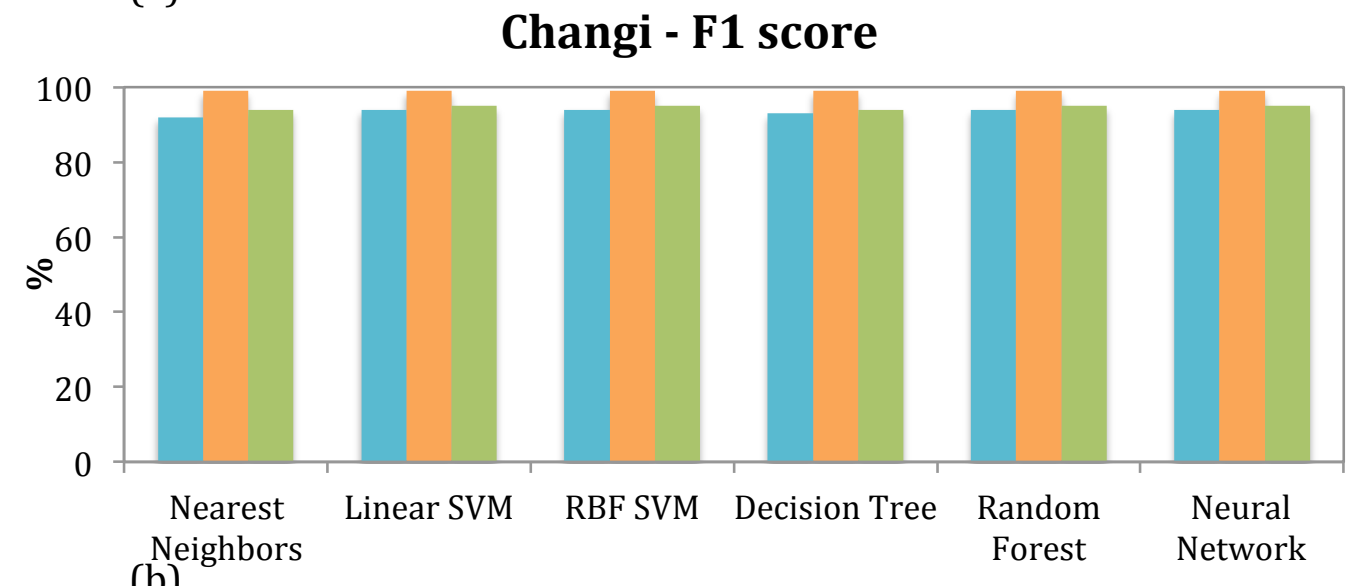

(b)

Paya Labar - F1 score

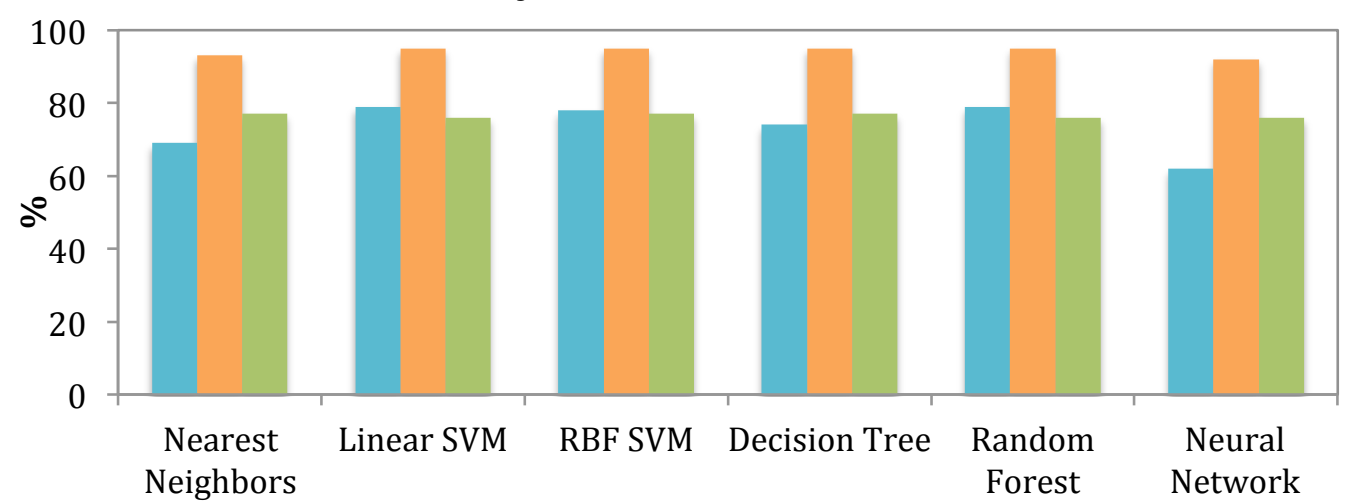

(c)

\section{Seletar - F1 score}

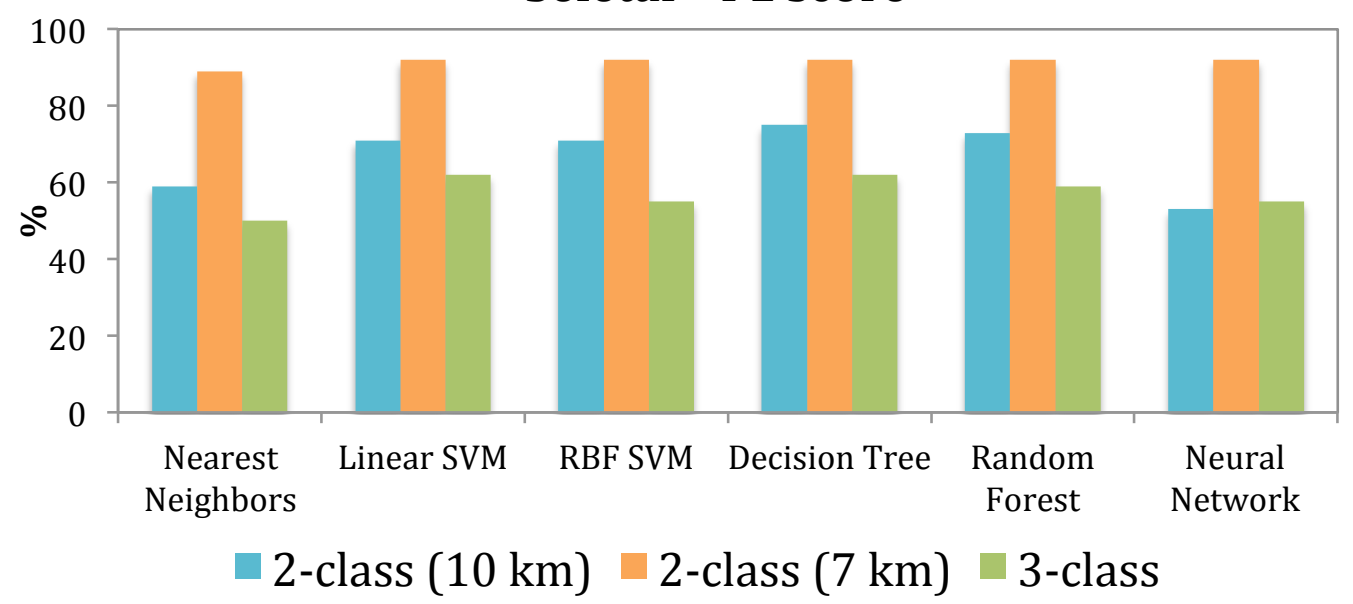

Figure S5. The $\mathrm{F}_{1}$ score in 6 Machine Learning algorithms for two 2-class $(7 \mathrm{~km}$ or $10 \mathrm{~km}$ visibility as a breakpoint) and one 3-class classifications haze prediction in (a) Changi, (b) Paya Labar, and (c) Seletar. 


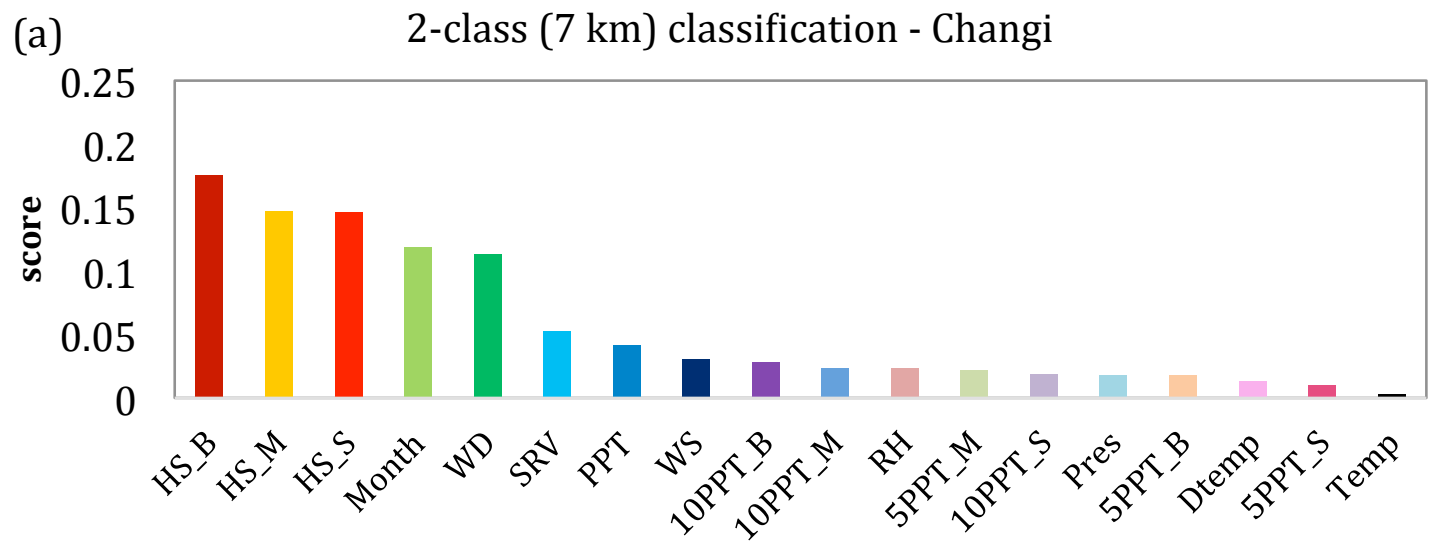

(b) 2-class $(7 \mathrm{~km})$ classification - Payalabar

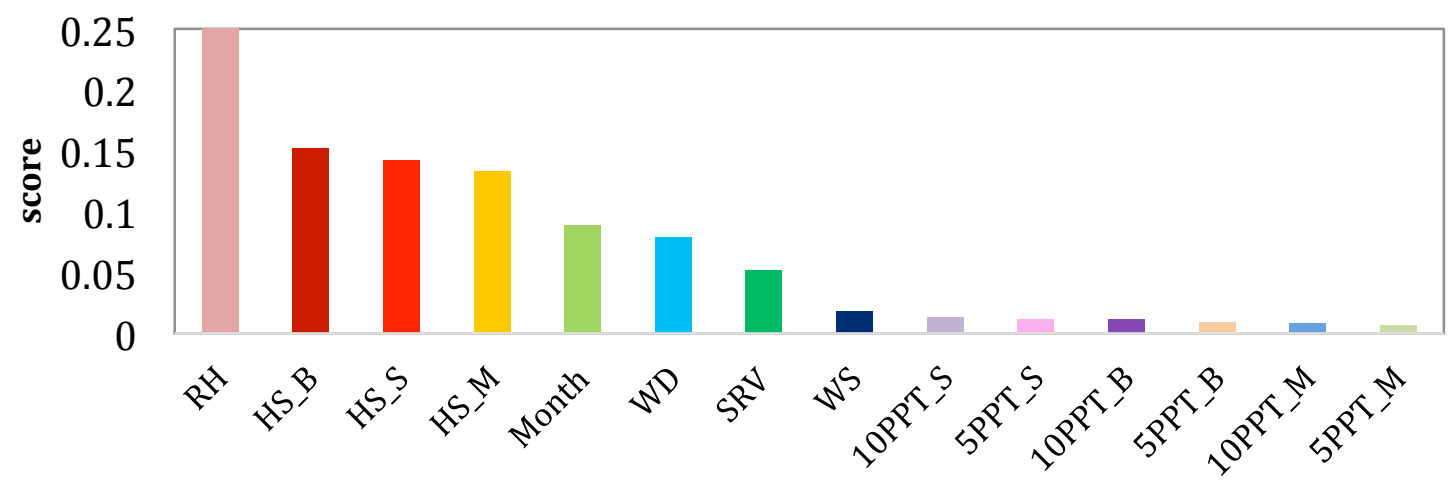

(c) 2-class (7 km) classification - Seletar

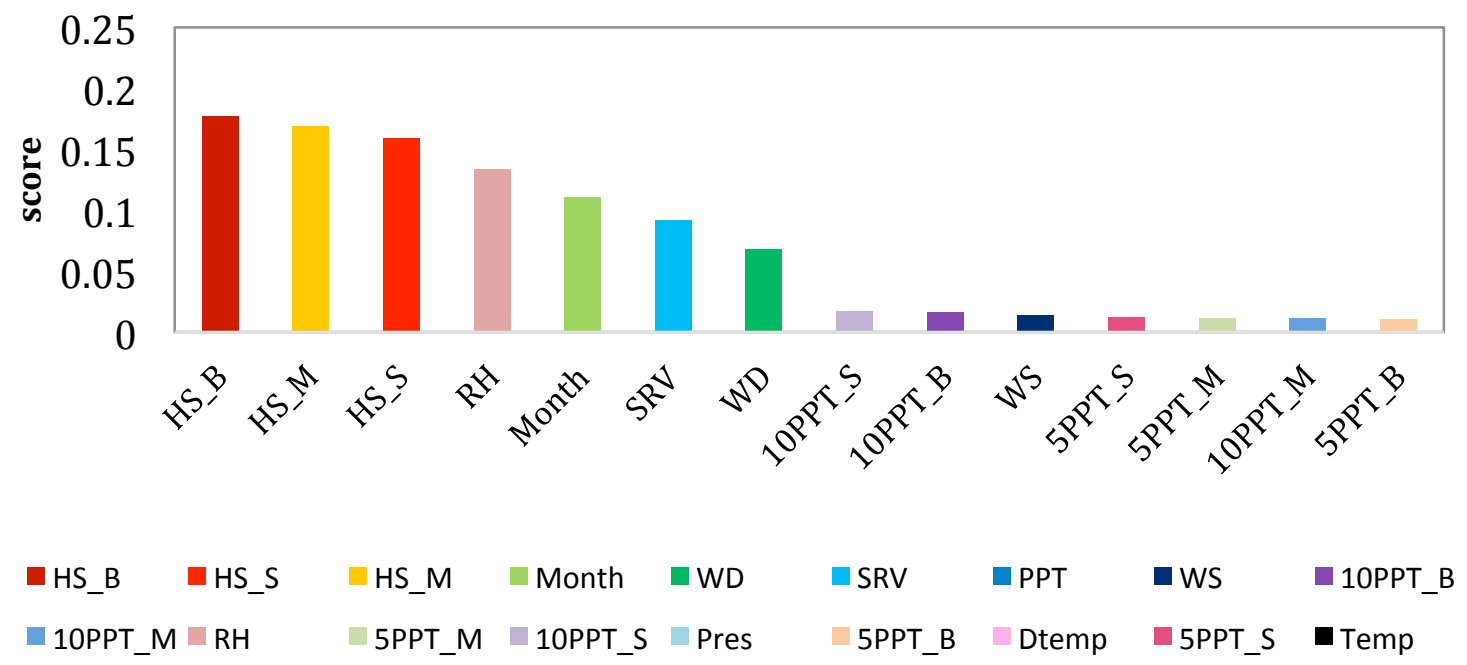

Figure S6. Feature importance by using 2-class classification Random Forest algorithm for (a) Changi, (b) Paya Labar, and (c) Seletar data. Desired outputs, haze versus non-haze events, are defined by using visibility $7 \mathrm{~km}$ as a breakpoint. Full name of each input feature are listed in Table S5. 


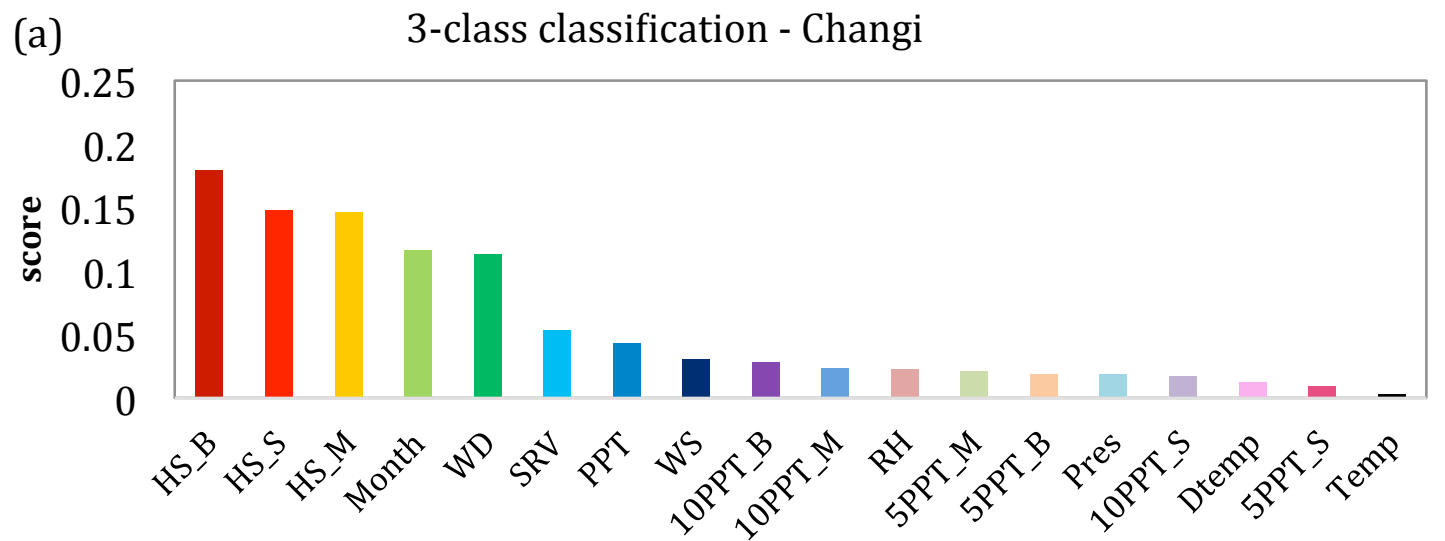

(b) 3-class classification - Payalabar

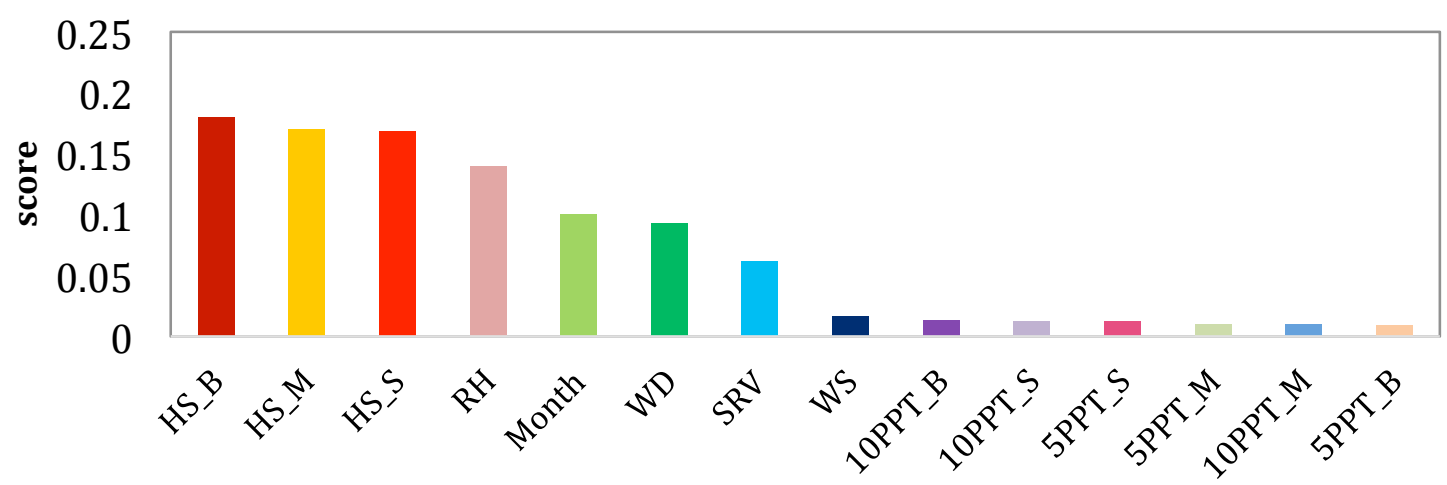

(c) 3-class classification - Seletar

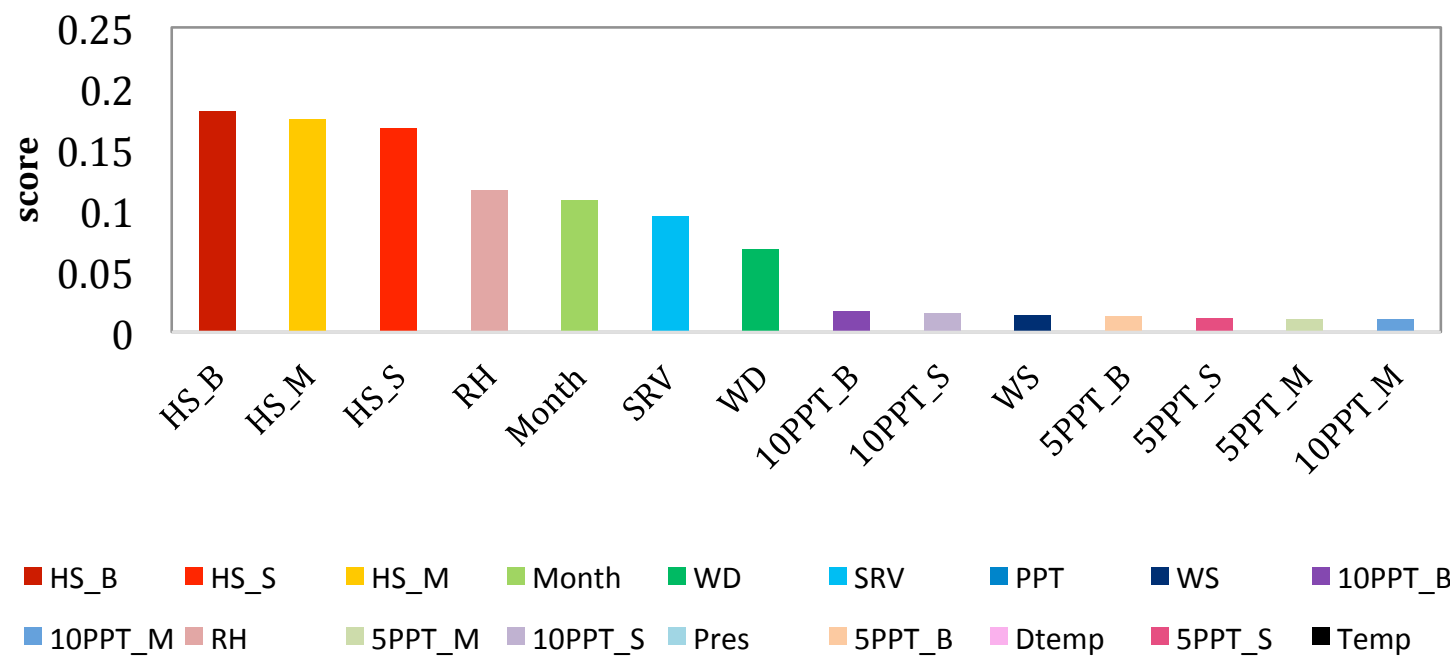

Figure S7. Feature importance by using 3-class classification Random Forest algorithm for (a) Changi, (b) Paya Labar, and (c) Seletar data. Desired outputs, severe haze, haze, and non-haze events, are defined by using visibility 7 and $10 \mathrm{~km}$ as breakpoints. Full name of each input feature are listed in Table S5. 


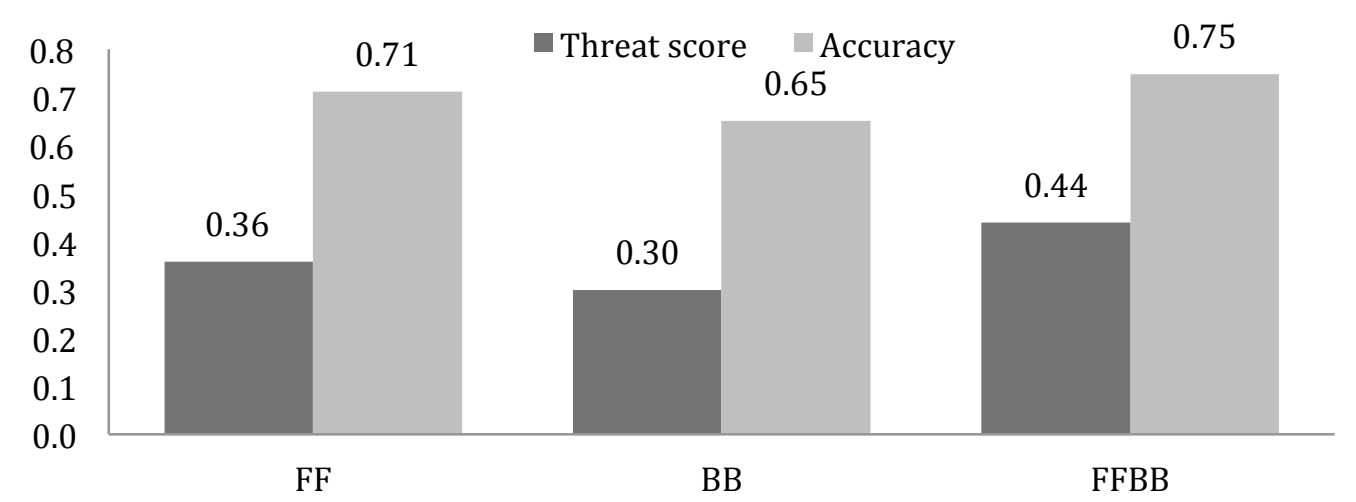

Figure S8. The mean value of accuracy and Threat score of modeled LVDs among 50 ASEAN cities in three experiment, FF, BB, and FFBB. 


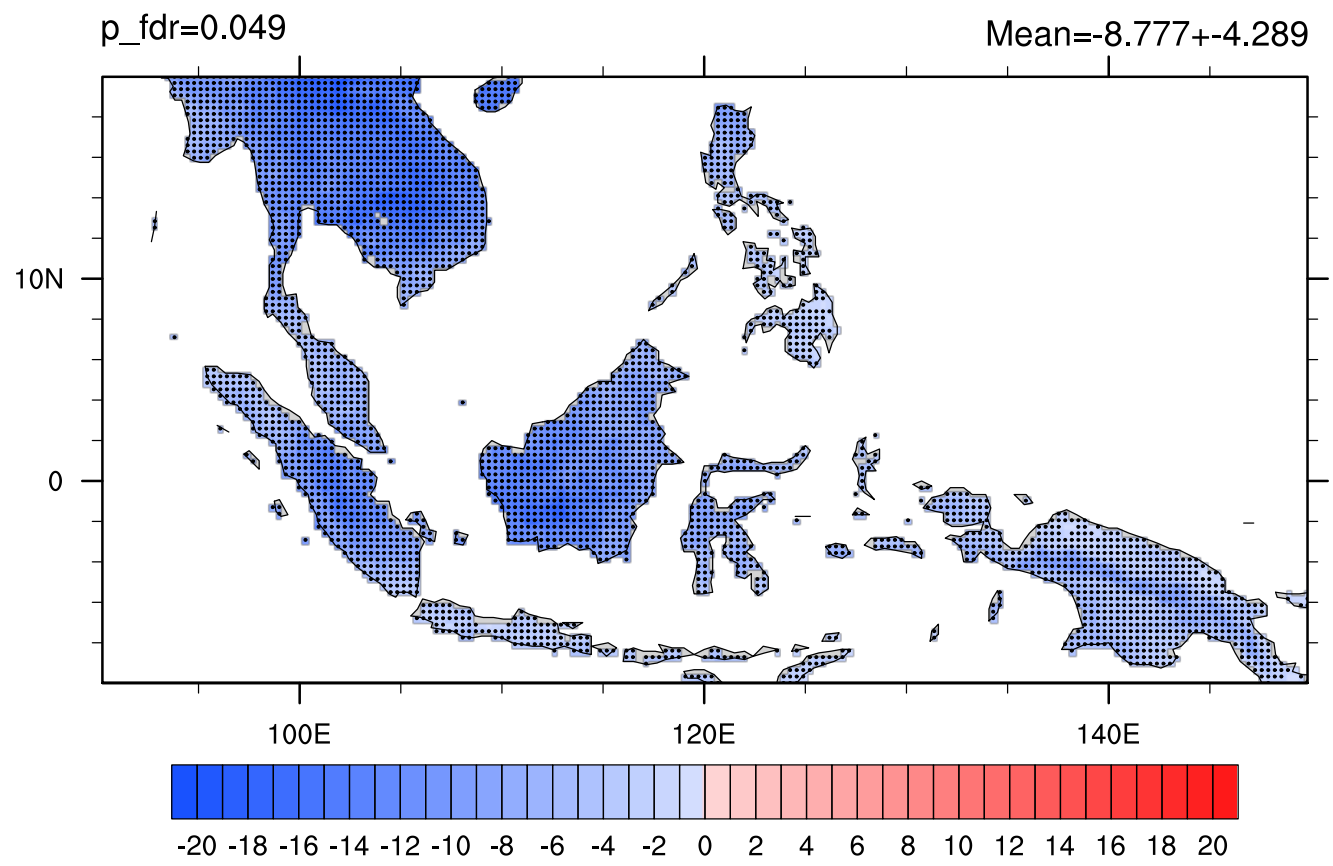

Figure S9. Total monthly mean downward shortwave radiation $\left(\mathrm{W} \mathrm{m}^{-2}\right)$ between FFBB and FF (FFBB-FF) simulations during 2002-2008. Black dots indicate differences that are statistically significant at a significance level of $\alpha_{\mathrm{fdr}}=0.05$ after controlling for the false discovery rate (FDR) (Benjamini and Hochberg, 1995; Wilks, 2016). The two-tailed pvalues are generated by Welch's t-test, using monthly mean data as the input. The approximate $\mathrm{p}$-value threshold, $\mathrm{p}_{\text {fddr, }}$ area mean and standard deviation (over land only) are recorded in the map above. 


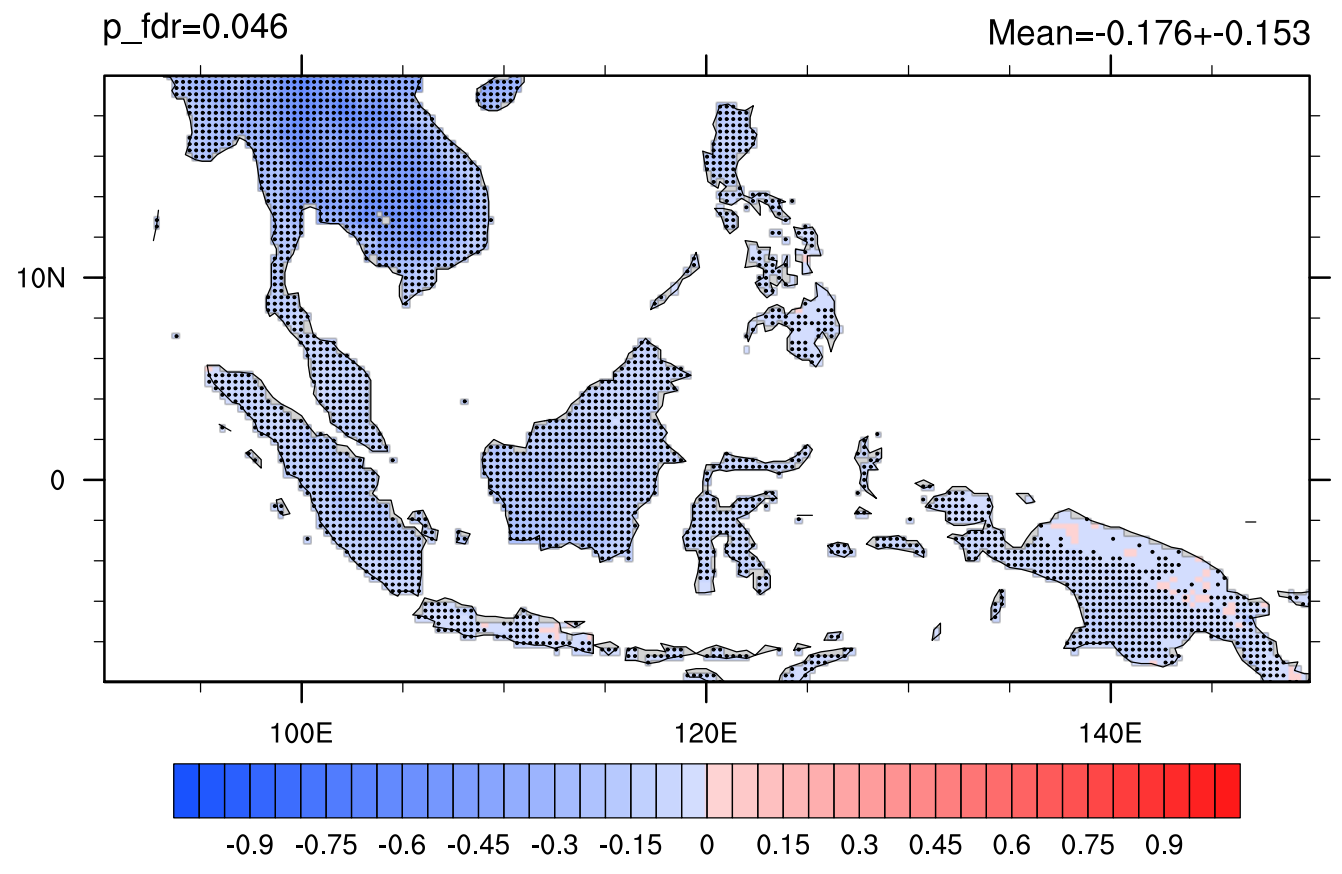

Figure S10. Total monthly mean surface skin temperature $(\mathrm{K})$ between FFBB and FF (FFBB-FF) simulations during 2002-2008. Black dots indicate differences that are statistically significant at a significance level of $\alpha_{\mathrm{fdr}}=0.05$ after controlling for the false discovery rate (FDR) (Benjamini and Hochberg, 1995; Wilks, 2016). The two-tailed pvalues are generated by Welch's t-test, using monthly mean data as the input. The approximate $\mathrm{p}$-value threshold, $\mathrm{p}_{\text {fddr, }}$ area mean and standard deviation (over land only) are recorded in the map above. 


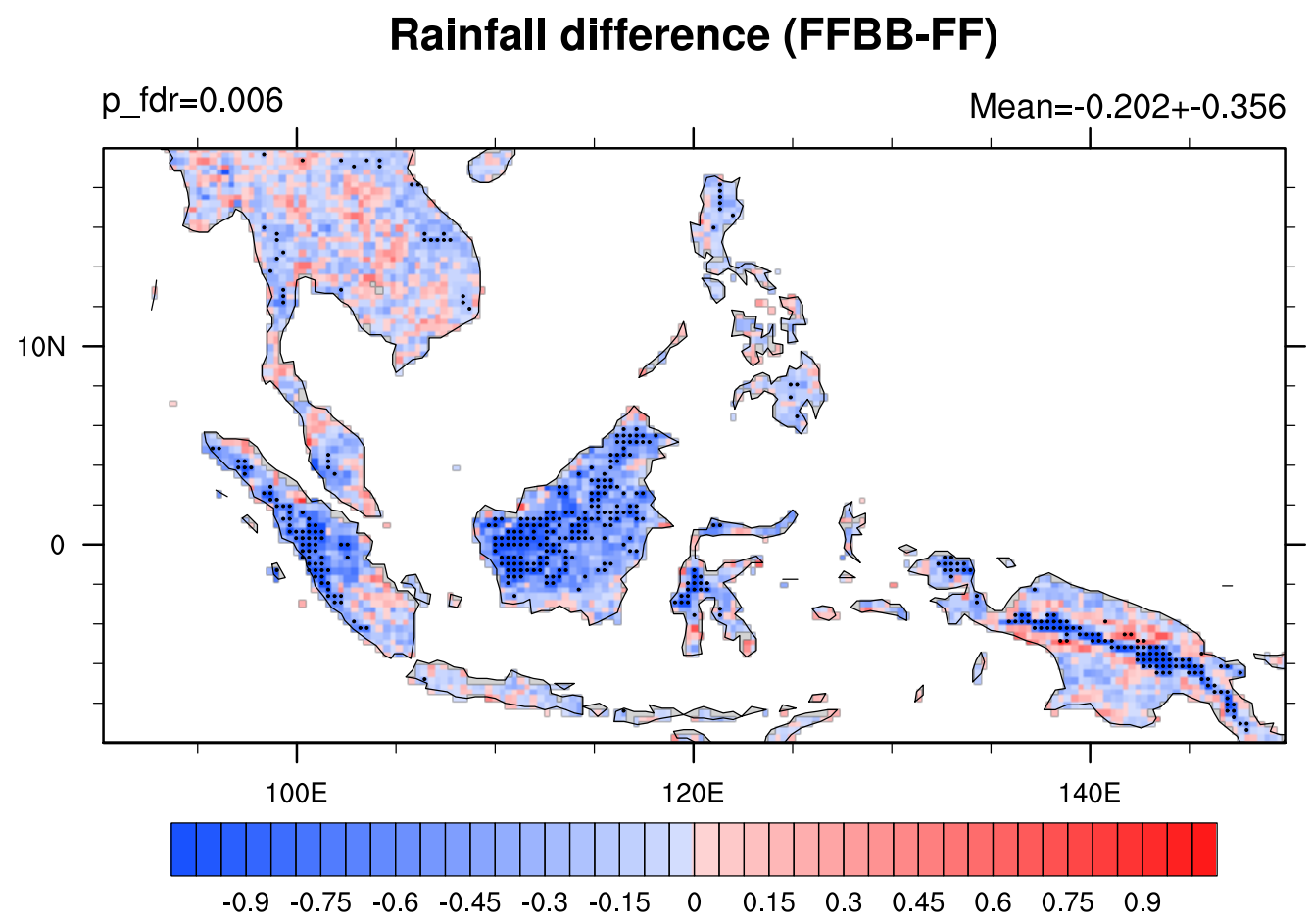

Figure S11. Total monthly mean precipitation differences $\left(\mathrm{mm} \mathrm{day}^{-1}\right)$ between FFBB and FF simulations during 2002-2008. Black dot indicates differences that are statistically significant at a significance level of $\alpha_{\mathrm{fdr}}=0.05$ after controlling the false discovery rate (FDR) (Benjamini and Hochberg, 1995; Wilks, 2016). The two-tailed p values are generated by Welch's $t$ test, using monthly mean data as the input. The approximate $p$ value threshold, p_fdr, and area mean and standard deviation (over land only) are written in above the map. 
Reference

Allwine, K. J., and Whiteman, C. D.: Single-station integral measures of atmospheric stagnation, recirculation and ventilation, Atmospheric Environment, 28, 713721, http://dx.doi.org/10.1016/1352-2310(94)90048-5, 1994.

Benjamini, Y., and Hochberg, Y.: Controlling the False Discovery Rate: A Practical and Powerful Approach to Multiple Testing, Journal of the Royal Statistical Society. Series B (Methodological), 57, 289-300, 1995.

Berg, P., Moseley, C., and Haerter, J. O.: Strong increase in convective precipitation in response to higher temperatures, Nature Geosci, 6, 181-185, http://www.nature.com/ngeo/journal/v6/n3/abs/ngeo1731.html supplementary-information, 2013.

Malaysia, D. o. E.: A Guide To AIr Pollutant Index in Malaysia, 4 ed., edited by: Malaysia, D. o. E., 18 pp., 2000.

Wang, C.: Anthropogenic aerosols and the distribution of past large-scale precipitation change, Geophysical Research Letters, 42, 10,876-810,884, 10.1002/2015GL066416, 2015.

Wilks, D. S.: "The Stippling Shows Statistically Significant Grid Points": How Research Results are Routinely Overstated and Overinterpreted, and What to Do about It, Bulletin of the American Meteorological Society, 97, 2263-2273, 10.1175/BAMS-D-15-00267.1, 2016. 